\title{
CONTRATOS DE CONCESIÓN MERCANTIL DE AGENCIA Y FRANQUICIA INTERNACIONAL QUE SE EJECUTAN EN COLOMBIA*
}

DOI: http://dx.doi.org/10.17981/juridcuc.11.1.2015.12

Recibido: 04 de Mayo de 2015 / Revisado: 27 de Julio de 2015 / Aceptado: 28 de Julio de 2015

\author{
José Luis Zúñiga Ordoñez ${ }^{* *}$ \\ Universidad Cooperativa de Colombia - Sede Popayán
}

Puede citar el presente artículo así: / To reference this article:

Zuñiga, J. (2015). Contratos de Concesión Mercantil de Agencia y Franquicia Internacional que se ejecutan en Colombia. Jurídicas CUC, 11(1), 267-292. doi: http://dx.doi.org/10.17981/juridcuc.11.1.2015.12

\section{Resumen}

Los contratos de concesión comercial son una forma de manifestación de la globalización de la economía y un claro ejemplo de expansión empresarial, concretamente los negocios de agencia comercial y franquicia son modelos que materializan los objetivos de los empresarios de llegar a más consumidores en varios países. Sin embargo, cuando los negocios traspasan fronteras, se pueden encontrar normas estatales imperativas que impiden la expresión de la autonomía privada, tales como las normas que regulan los efectos al finalizar el contrato de agencia del Código de Comercio Colombiano. El modelo de franchising en varios países no tiene regulación expresa, entre ellos Colombia, en ese escenario la autonomía privada juega un papel preponderante, a lo cual, el franquiciado, de menor poder decisorio que el franquiciante, debe estar atento a las estipulaciones pactadas a fin de que no le sean perjudiciales, para lo cual, es importante el conocimiento de los modelos normativos que se han elaborado por instituciones internacionales al respecto.

\section{Palabras clave:}

Franquicia, franchising, agencia comercial, contrato internacional, Derecho internacional privado, Derecho mercantil internacional.

\footnotetext{
"Artículo de reflexión realizado con recursos del autor.
}

** Docente de tiempo completo de la Universidad Cooperativa de Colombia, sede Popayán, y abogado de la misma Universidad. Especialista en Derecho Comercial de Universidad de San Buenaventura y Pontificia Bolivariana; Magister en Derecho, Universidad Sergio Arboleda., Correo electrónico: jose.zunigao@campusucc.edu.co 


\title{
COMMERCIAL AGENCY AND INTERNATIONAL FRANCHISE AGREEMENTS EXECUTED IN COLOMBIA
}

\begin{abstract}
Franchise agreements are instruments of the global economy and a clear example of business expansion. In this sense, the agreement for commercial agency and franchising help to meet the objectives of entrepreneurs in order to reach more consumers in more countries. However, in cross-border business transactions, we may encounter norms which restrict private autonomy, as the norms which regulate the termination of the agency agreement in the Code of Commerce of Colombia. In some countries the franchising model is not explicitly regulated, for instance, in Colombia private autonomy plays a prevalent role, that is, the franchisee must be fully aware of the provisions agreed to avoid unfair contracts. Thus, it is relevant to learn about the legal models created in this domain by the international institutions.
\end{abstract}

\section{Keywords:}

Franchise, Franchising, commercial agency, international agreement, international private law, international commercial law. 
CONTRATOS DE CONCESIÓN MERCANTIL DE AGENCIA Y

\section{INTRODUCCIÓN}

Sin lugar a dudas, hoy por hoy los contratos de agencia comercial y franquicia son de las más destacadas alternativas jurídicas, a efecto de que los empresarios puedan expandir sus servicios y aumentar su clientela, así como posicionar sus productos, por lo cual, es posible que empresarios extranjeros quieran extender puntos de negocio en nuestro país. En tales contratos tendrían uno o más elementos extranjeros, por lo tal, serán contratos internacionales, que de ser ejecutados en Colombia, inicial y mayoritariamente la ley aplicable será la colombiana. En el presente documento se estudiará de qué manera pueden las partes pactar una ley aplicable diferente a la nacional, evitando regulaciones proteccionistas en el caso del contrato de agencia y aproximándose a modelos normativos uniformes creados por el Instituto Internacional para la Unificación del Derecho Privado (UNIDROIT).

Para la celebración y ejecución en Colombia del contrato de franquicia, por ser un contrato atípico, se indaga sobre los modelos normativos uniformes y de los principios generales del derecho comercial, buscando un punto de equilibrio en las obligaciones inter partes y tratando de dar equidad al franquiciado, quien podría sufrir estipulaciones abusivas, en especial en cuanto se refiere al deber de la información que debe brindar el franquiciante, la cual debe ser ajustada a la realidad, en cuanto a las expectativas económicas del negocio al que aspire el franquiciado para que lo motive a tomar la decisión de celebrar el contrato.

\section{Criterio de internacionalidad en los contratos de agencia comercial y franquicia}

El Derecho internacional privado básicamente se encarga del estudio de las relaciones jurídicas entre particulares con elementos de extranjería relevantes, de tal ejercicio deductivo se concluye si el contrato es internacional.

Los elementos de extranjería presentes en la relación jurídica pueden emerger de las personas que intervienen en ella, verbigracia el matrimonio de personas de diferente nacionalidad; los bienes objeto del negocio jurídico, como cuando un colombiano compra un inmueble en Caracas, Venezuela, realizando la escritura pública en una notaría de Bogotá; el lugar donde ocurre determinado hecho jurídico aunado a las personas que inter- 
vienen en el mismo, como puede ser el matrimonio de dos colombianos en España, o la muerte de un Colombiano en Perú, con herederos en ambos países. En esas complejas situaciones el método de reglamentación mayormente aceptado es el de la técnica conflictual o regla de conflicto con la cual se determina cuál es la ley aplicable al negocio jurídico internacional. Conviene mencionar que otro punto de conexión y de uso en manifestaciones jurídicas de la actualidad es el que refiere a los nexos más estrechos con el contrato o negocio jurídico.

Las relaciones internacionales entre particulares donde no existe intercambio comercial son una cara de la moneda y, la otra cara, la compone el comercio internacional, el cual ha ido desarrollándose a la par de las políticas de economía de mercado y apertura de los capitales en los países democráticos, contribuyendo a nuevos conceptos de empresa y establecimiento alejados de los tradicionales en el derecho interno. Los empresarios apoyados en el libre mercado han desarrollado sus modelos de negocio en varios países. "Los empresarios que actúan en todos los lugares de la tierra, demandan libertad de establecimiento, para ellos y sus empresas, acceso a los mercados extranjeros, reglas básicas idénticas y principios generales comunes que orienten sus negocios y sus expectativas" (Ravassa, 2004, p. 118).

Ese es el escenario donde se desarrollan los contratos de agencia y franquicia, siendo menester tratar de aproximarnos a lo que se pueda definir como franquicia y agencia internacionales.

En este orden de ideas, existen doctrinas que estudian y tratan de definir qué es un contrato internacional, siendo una de las más sencilla de entender la "tesis del elemento extranjero puro", para la cual, un contrato es internacional cuando "...presenta al menos, un elemento extranjero, cualquiera que sea dicho elemento" (Carrascosa citado por Oviedo, 2007, p. 2). Como tal, en una relación de negocios como las que estamos estudiando, se podrían encontrar elementos de extranjería en los sujetos que celebran el contrato, es decir, la empresa multinacional que quiere expandir sus negocios en varios países, o la empresa colombiana, que a su vez, proyecta colocar sus productos y servicios en otros Estados. El carácter de diferente nacionalidad de las partes, o la celebración y ejecución del contrato en un país diferente será el factor que le pondrá el rótulo de extranjera a la relación jurídica; esta tesis se basa en la presencia del elemento de extranjería, no el contenido mismo de la relación. 
En la ejecución de los contratos, cualquiera que sea su denominación, los conflictos o controversias son inherentes a su naturaleza económica y a la contraposición de intereses. En tal situación ha surgido una discusión constante, y es, cuál será el juez competente y cuál la ley aplicable; esta situación ha pretendido ser solucionada con el Derecho internacional privado, en verdad con muy poco éxito por lo inadecuado que resulta la aplicación de la regla de conflicto, pues será siempre un juez y una ley estatal la que resuelva de fondo la situación con elementos internacionales, en el entendido que materialmente no existen normas nacionales que prevean relaciones jurídicas de corte internacional. El Derecho internacional privado, dada su naturaleza estatal, no tiene la estructura material para regular adecuadamente relaciones ius-privatistas internacionales. Al respecto dice Pérez (2002): "se trata de las relaciones jurídicas que, o bien por las personas que intervienen, por el objeto sobre el que versan, o bien, por el modo en que se producen, no agotan sus consecuencias en una única esfera jurídica". Llevando a una regulación no suficientemente adecuada, teniendo que recurrir no en pocas ocasiones a la concepción de los contratos atípicos, o la aplicación e interpretación de los principios generales del derecho.

También han mencionado, entre otros autores, Oviedo (2007) y Carrascosa (2003) la "tesis del efecto internacional", la cual dice que un contrato es internacional cuando produce efectos conectados con otros países o afecta a los intereses del comercio internacional. Sin embargo, tales intereses no dejan de ser un concepto teleológico que no ofrece seguridad al momento de su aplicación al caso concreto. No obstante, en cuanto a Derecho mercantil internacional se refiere, se cree que uno de los intereses de este ordenamiento jurídico conocido como nueva lex mercatoria, busca que prevalezca la autonomía privada y la uniformidad en la aplicación de los instrumentos normativos creados por organizaciones internacionales, tales como UNICITRAL ${ }^{1}, \mathrm{CCI}^{2}$ y UNIDROIT, algunos de ellos basados en los usos y costumbres mercantiles internacionales: es decir, la interpretación de las normativas en el comercio internacional debe siempre apoyarse en los instrumentos supraestatales, dejando el Derecho privado internacional de corte estatal como última alternativa.

\footnotetext{
${ }^{1}$ United Nations Commission for the Unification of International Trade Law (CNUDMI en español).

${ }^{2}$ Cámara de Comercio Intenacional
} 
Será menester en el orden lógico de interpretación, la identificación de los elementos de extranjería en los contratos de agencia comercial y franquicia en los componentes de la relación jurídica establecida, a efecto de considerarlo internacional.

Desde el punto de vista del Derecho internacional privado, un contrato de franquicia será internacional por el solo hecho de que sea celebrado por "dos nacionales de diferentes países" (Londoño 2005, p. 139) es decir, la sola presencia de la nacionalidad extranjera de una de las partes sería suficiente. Sin embargo, para la doctrina del Derecho mercantil internacional, no basta ese solo elemento, pues deja de lado otros elementos de extranjería de común presencia como son el lugar de ejecución en país diferente al de su celebración, o el establecimiento de las partes en diferentes países $\left(\mathrm{CVCIM}^{3}, 1980\right.$, Art. 1). No se puede olvidar que los contratos que estamos abordando requieren de la apertura de uno o varios establecimientos de comercio, efecto propio de un fin económico de expansión empresarial.

Atendiendo a la posición doctrinal de la distinta nacionalidad, si el contrato de franquicia lo celebraran dos empresarios de Estados Unidos para ejecutarse en Colombia, no sería internacional, más en este supuesto, los empresarios tendrían que aceptar una legislación extranjera, la colombiana, dado el lugar de ejecución del contrato, incluso si se celebrara en Estados Unidos, lo anterior, por lo dispuesto en el artículo 869 del Código de Comercio (Decreto 410, 1971) ${ }^{4}$. En conclusión, esta teoría es insuficiente, no se ajusta a las posibilidades fácticas que se presentan en las relaciones del comercio internacional ni a sus instrumentos jurídicos más relevantes.

El desarrollo que se viene presentando en cuanto a la apertura de franquicias en los países, hace de este contrato uno de alta disposición de internacionalidad por ser un modelo de expansión de la comercialización de bienes y servicios que ha encontrado en este modelo el mecanismo adecuado para el crecimiento de las cadenas de distribución y la expansión de los puestos de venta a los consumidores finales.

\footnotetext{
${ }^{3}$ Convención de Viena sobre Compraventa Internacional de Mercaderías.

${ }^{4}$ Artículo 869. Ejecución de Contratos Celebrados en el Exterior con Cumplimiento en Colombia: La ejecución de los contratos celebrados en el exterior que deban cumplirse en el país, se regirá por la ley colombiana.
} 
El contrato de agencia internacional, ejecutado en Colombia, ofrece la compleja situación de ser obligatoriamente regulado por la ley colombiana, según lo expresado por el artículo 1328 (Decreto 410, 1971). La autonomía privada no tiene los alcances que ofrecen la (CVCIM, 1980) ${ }^{5}$, Convenio de Roma sobre Ley aplicable a las obligaciones contractuales (1980) ${ }^{6}$, así como los Principios UNIDROIT sobre los Contratos Comerciales Internacionales $(2010)^{7}$. Esta situación la analizaremos más adelante.

Son diversos los elementos de extranjería que se pueden presentar cuando de contratos de concesión se trata, sin embargo, la norma de conflicto del artículo 869 del Código de Comercio, como se ha dicho, sería un obstáculo para el empresario extranjero que no desea las normas colombianas, con el agravante que en el país no existen normas regulatorias del contrato de franquicia, o las normas protectoras del agente en cuanto a la agencia comercial se refiere en virtud del artículo 1328 (Decreto 410, 1971).

La doctora Zapata (2010) considera que para cualquier contrato celebrado en el exterior y ejecutado en Colombia, las partes podrían elegir la ley aplicable, en el entendido que el artículo 869 del Código de Comercio, no es en sí mismo, una norma de carácter imperativo, por lo tanto, "la aplicación de las normas locales a las relaciones internacio-

\footnotetext{
${ }^{5}$ Artículo 6. Las partes podrán excluir la aplicación de la presente Convención o, sin perjuicio de lo dispuesto en el artículo 12, establecer excepciones a cualquiera de sus disposiciones o modificar sus efectos.

${ }^{6}$ Artículo 3. Libertad de elección. 1. Los contratos se regirán por la ley elegida por las partes. Esta elección deberá ser expresa o resultar de manera cierta de los términos del contrato o de las circunstancias del caso. Para esta elección, las Partes podrán designar la ley aplicable a la totalidad o solamente a una parte del contrato. 2. Las partes podrán, en cualquier momento, convenir que se rija el contrato por una ley distinta de la que lo regía con anterioridad bien sea en virtud de una elección anterior según el presente artículo, o bien en virtud de otras disposiciones del presente Convenio. Toda modificación relativa a la determinación de la ley aplicable, posterior a la celebración del contrato, no obstará a la validez formal del contrato a efectos del artículo 91. y no afectará a los derechos de terceros. 3. La elección por las partes de una ley extranjera, acompañada o no de la de un Tribunal extranjero, no podrá afectar, cuando todos los demás elementos de la situación estén localizados en el momento de esta elección en un solo país, a las disposiciones que la ley de ese país no permita derogar por contrato, denominadas en lo sucesivo "disposiciones imperativas». 4. La existencia y la validez del consentimiento de las partes en cuanto a la elección de la ley aplicable se regirán por las disposiciones establecidas en los artículos 8, 9 y 11.
}

${ }^{7}$ Preámbulo: Estos Principios deberán aplicarse cuando las partes hayan acordado que su contrato se rija por ellos.(*) Artículo 1.5 (Exclusión o modificación de los Principios por las partes) Las partes pueden excluir la aplicación de estos Principios, así como derogar o modificar el efecto de cualquiera de sus disposiciones, salvo que en ellos se disponga algo diferente. 
nales resulta en algunos casos razonable y conveniente, pero no precisamente en el ámbito contractual en el que los actores buscan precisión sobre las normas y el foro competente. Se considera que resultan más aptas para regir una relación internacional las normas especialmente concebidas para el comercio internacional, aplicadas y analizadas desde una perspectiva internacional.” (2010, p. 31)

En ese punto pareciera que se podría aplicar al contrato de agencia que se ejecuta en Colombia normas diferentes a la lex fori, sin embargo, la misma autora es categórica al afirmar que en el contrato mencionado, "la ley autonomía en DIP" no es obstáculo para que se apliquen normas nacionales de orden público, verbigracia el artículo 1328 (Decreto $410,1971)$, pues la norma menciona que "para todos los efectos" los contratos de agencia quedan sujetos a la ley colombiana, justificándose en la protección que el Estado colombiano proporciona al agente en cuanto a las prestaciones después de la terminación del contrato. Incluso la jurisprudencia de la Corte Suprema de Justicia considera de orden público el artículo 1328 (Decreto 410, 1971), por lo cual el legislador no concibe relevante en absoluto el lugar de celebración y la nacionalidad de las partes (Expediente 4701, 1995).

No obstante lo mencionado por la respetada tratadista, si las partes en un contrato de agencia comercial con elementos de extranjería presentes de igual o mayor relevancia que el lugar de su ejecución "lex loci executionis" no eligen ley aplicable mas sí cláusula compromisoria y se dan los requisitos para que el arbitraje sea internacional, los árbitros se podrán apartar de la normatividad colombiana.

Según lo establecido en la Ley 1563 (2012),

Se entiende que el arbitraje es internacional cuando:

a. Las partes en un acuerdo de arbitraje tengan, al momento de la celebración de ese acuerdo, sus domicilios en Estados diferentes; o

b. El lugar del cumplimiento de una parte sustancial de las obligaciones o el lugar con el cual el objeto del litigio tenga una relación más estrecha, está situado fuera del Estado en el cual las partes tienen sus domicilios; o

c. La controversia sometida a decisión arbitral afecte los intereses del comercio internacional. (Ley 1563, 2012, Art. 62) 
De acuerdo con la norma trascrita, no se ve cómo los árbitros tengan que ceñirse a una norma local de manera obligatoria si esa no fue la intención de las partes. Tal imposición riñe con los fines del comercio internacional, por lo cual, los árbitros siguiendo el mandato del acuerdo arbitral, el cual goza de autonomía, deben seguir el sentir de las partes que los designaron, es decir, si las aquéllas no eligieron ley nacional aplicable, es porque no la desean. En ese orden de ideas, autores como Silva (2010) señalan que "cada vez con mayor frecuencia, quizás en razón del tecnicismo de muchos proyectos, las partes en los contratos internacionales sometidos a la CCI declaran que éstos no están sometidos a ningún derecho y que, por consiguiente, todo litigio deberá ser resuelto por los árbitros exclusivamente de conformidad con las cláusulas contractuales".

Ante la celebración de contratos de franquicia o agencia comercial con cláusula compromisoria, las condiciones en que se entiende la naturaleza internacional del arbitraje se han adecuado a los modelos de arbitraje existentes más representativos, verbigracia la Ley Modelo de la $\mathrm{CNUDMI}^{8}$, (1985, Art. 1).

En el caso hipotético que se ha planteado, las partes no han pactado ley aplicable a su contrato pero sí arbitraje internacional, tendrían entonces los árbitros que hacer la escogencia del foro. Según los instrumentos legales y la doctrina existen los siguientes métodos, nos referimos a la técnica conflictual del Derecho internacional privado, de la cual el tribunal tomará distancia prefiriendo los principios UNIDROIT sobre los Contratos Comerciales Internacionales, la Ley Modelo de la CNUDMI sobre el arbitraje comercial internacional, entre otros modelos normativos uniformes. No se puede olvidar que los árbitros, en virtud del principio de habilitación, tienen jurisdicción, por lo cual deben fallar como función esencial, pero desde luego que podrán apoyarse en las disposiciones que sobre el contrato de agencia comercial ha publicado la CCI sin elegir la normatividad de ningún país donde las partes tengan sus establecimientos a efecto de tener mayor independencia y atendiendo el mandato de ser árbitros internacionales, que sería lo más adecuado.

${ }^{8}$ Comisión de las Naciones Unidas para el Derecho Mercantil Internacional. 
El arbitraje mercantil internacional, como método alternativo de solución de controversias del comercio internacional, debe propender por la búsqueda de la uniformidad como atributo y fin del marco legal de los negocios en el mercado mundial, por lo tanto, sería contradictorio que se sometiera a los designios del derecho internacional privado o de leyes estatales imperativas cuando la relación jurídica tiene varios elementos de extranjería y se trata de negocios entre particulares. Esa finalidad es acogida por el último marco normativo sobre arbitraje promovido por el Congreso colombiano con la Ley 1563 (2012), Estatuto de Arbitraje Nacional e Internacional en su artículo 64, donde claramente se estipula que "en la interpretación del arbitraje internacional habrán de tenerse en cuenta su carácter internacional y la necesidad de promover la uniformidad de su aplicación”.

\section{De la agencia comercial}

Contrato regulado en la legislación colombiana, es decir tiene tipicidad y denominación, a diferencia del contrato de franquicia que no tiene regulación específica en nuestra legislación, a pesar de su amplia difusión en el mercado. El contrato de agencia es una forma de mandato, dado su ubicación en el Código de Comercio Colombiano, Libro Cuarto, Título XIII; que desarrolla el contrato de mandato en general, de la definición normativa, que dice se trata de un encargo de promover o explotar negocios, que recibe un comerciante.

Sin embargo, el profesor Arrubla (2004) manifiesta que la agencia comercial, a pesar de su ubicación en el Código de comercio, no hace mención, en ninguno de los artículos que desarrollan este contrato, que sea una especie de mandato, como sí se manifiesta en la regulación de los contratos de comisión y preposición como "hijos del mandato". Lo cual es una falta de técnica legislativa según el mencionado autor.

La regulación de la agencia comercial es tomada de la legislación italiana, la cual no contempla al contrato de agencia como una suerte de mandato, en relación con esta situación, comenta el profesor Mesineo (1971): "el contrato de agencia se distingue del mandato por el dato decisivo de que el agente no realiza actos jurídicos, sino que procura negocios, salvo el caso de que se trate de agente con representación". 
Ahora bien, la discusión de si el contrato que estamos estudiando es o no una forma de mandato, no es el objeto de esta investigación, sin embargo tiene algún grado de importancia, dado que dependiendo de la cultura jurídica a la que pertenezca alguna de sus partes pueden interpretarse sus alcances de manera diversa en el sentido de su asimilación al contrato de mandato, pues, en caso de vacíos de regulación se llenarían con disposiciones de aquel contrato.

Aunque otros doctrinantes, como Escobar (1987), optan por considerar a la agencia como una forma de mandato, precisamente por la ubicación en el Código de Comercio, aunado al artículo 20, numeral 8. Por otro lado Ripert, citado por Farina (1999), dice: "el agente comercial es un mandatario que trata con la clientela en nombre de un industrial o de un comerciante. Este mandato es comercial, porque se acepta a título interesado y se confiere para la celebración de un acto de comercio."

Así mismo, el doctor Vallejo (1999) afirma que: "la puerta de entrada a nuestro estudio es el contrato de mandato y el instituto jurídico de la representación (que se relaciona estrechamente con aquel) sin cuyo previo conocimiento es imposible entender el contrato de agencia comercial".

El objetivo de este estudio es analizar cómo se regula el contrato de agencia comercial internacional, es decir, cuando en la relación se ponen en evidencia uno o más elementos de extranjería relevantes, en el entendido que el problema del Derecho internacional privado y del Derecho mercantil internacional, en cuanto a su regulación, es el tema de la ley aplicable, donde pueden confrontarse el principio de la autonomía privada y de la norma de conflicto o técnica conflictual que obedece a parámetros imperativos.

En el contrato de agencia se pueden encontrar elementos de extranjería tales como la nacionalidad extranjera del empresario que busca el posicionamiento de sus marcas, productos o servicios en el país; que el contrato se celebre en país extranjero y se plantee más de un país para la promoción de bienes y servicios, entre ellos el nuestro; o que para la fabricación de productos se requiera el concurso de más de un establecimiento ubicado en más de un país, por nombrar algunos. Sin embargo, el artículo 1328 del Código de comercio es un obstáculo para la elección de ley aplicable por los contratantes. 
La mencionada norma advierte que para "todos los efectos", los contratos de agencia comercial que se ejecuten en Colombia quedan sujetos a las leyes colombianas. Creemos que aquella disposición, considerada por algunos tratadistas de orden público es la justificación para impedir que una legislación diferente a la nacional regule este contrato. De forma particular, se considera errónea y exagerada la concepción de comparar al agente como si fuese un trabajador, al margen de la realidad actual, donde verdaderas compañías pueden desarrollar las labores de promoción y explotación, precisamente cuando se trata de empresas con productos y servicios de alto posicionamiento internacional, además que entre dos empresarios bien puede existir una posición de dominio mas no de subordinación, como en la relación laboral.

El agente, sea persona natural o jurídica, actúa de manera independiente, característica que aleja al contrato de agencia del de trabajo, además, la categoría comercial del mismo no justifica un excesivo proteccionismo por parte del Estado colombiano, lo que genera obstáculos para la inversión extranjera por medio de agencias comerciales. Sin embargo, mientras exista la norma mencionada se deberá sortear de alguna manera.

Según el artículo 1324 del Código de Comercio, se consagra una prestación económica a favor del agente a manera de indemnización, como si se tratara de una relación donde el empresario es la parte dominante sin excepción.

Según las obligaciones del agente de promover o explotar los negocios que interesan a un empresario, tiene como consecuencia que éste adquiere ingresos como producto de sus ventas, además de una clientela creciente, que de acuerdo con la calidad de la actividad del agente puede incluso fidelizarse, por esa razón puede inferirse dicha prerrogativa económica.

La tendencia normativa pone en evidencia su carácter proteccionista, incluso en las justas causas para la terminación del contrato que exigen como causal del empresario a este efecto, el grave incumplimiento del agente, mientras que para éste, el solo incumplimiento del empresario de sus obligaciones contractuales o legales es suficiente para su terminación. 
El escenario que ofrece la normativa colombiana sobre la agencia comercial en lo atinente a las prestaciones del artículo 1324, aunado al 1328, muestran unas normas de carácter imperativo, pero no estrictamente de orden público, pues los intereses de los agentes no consultan sectores sensibles de la sociedad. Pero al tratarse de la aplicación de dichas normas en el contexto internacional, se encuentra entonces otro valor jurídico importante, este es, el orden público internacional, para cuya definición el profesor Moya (2003, p. 144) elabora este corto concepto: "el orden público internacional de un Estado está conformado por el conjunto de normas que reclaman aplicación en todos los casos, dado el carácter superior de los intereses involucrados en su eficacia."

Este tipo de normas teleológicamente derivan su aplicación absoluta en cuanto el Estado mismo sostiene su aplicación a efecto de que se dé el cumplimiento de sus fines esenciales. No es el caso de un contrato comercial como el de agencia, diseñado para comerciantes y desarrollado por ellos mismos. La protección que ha constituido el Estado colombiano por medio de las normas expresadas, pueden incluso afectar la inversión extranjera generada por medio de este contrato, con las consecuencias económicas negativas que se puedan generar en la economía y el empleo; para poner un ejemplo, en el texto del tratado de libre comercio con Estados Unidos, específicamente en lo concerniente al Dealers Act, pactado en el anexo 11-E del capítulo 11 de Comercio Transfronterizo de Servicios, se exige la modificación de aquella normatividad en el punto que venimos mencionando.

Cuando se celebran contratos de agencia internacional, se piensa que deberían ser otros los principios que deban gobernar sus relaciones jurídicas, en el entendido que los intereses del comercio internacional, entre otros, los de buscar la armonía en la aplicación normativa, requieren un cambio de enfoque, que se aparte de parámetros eminentemente internos y se acerque al favorecimiento del comercio trasnacional.

Dice el profesor Parra (2001): "los Principios Generales del comercio internacional no son siempre principios subsidiarios del derecho estatal pudiéndose encontrar en ocasiones formando parte de los contratos, de forma no siempre lo suficientemente clara, sobre la base de la libertad de elección de las partes." Es el caso de las dominadas cláusulas direc- 
tas en las cuales se excluye de manera expresa la aplicación de la ley estatal, dando vía libre a los principios generales y usos del comercio internacional. En ese orden de ideas, debe darse una mirada diferente a disposiciones que para el derecho interno son imperativas, pero no de orden público interno, y por lo tanto, deben armonizarse según las tendencias del comercio internacional.

La Cámara de Comercio Internacional, ha elaborado el modelo de agencia internacional (ICC Model Commercial Agency Contract), estudios basados en la regulación que de este contrato existen en varios países en búsqueda de la unificación normativa, fin esencial del comercio internacional. En Europa existe la Directiva 86-653 del 18 de diciembre de 1986 de la antigua Comunidad Económica Europea, que regula lo referente al contrato de agencia para los países miembros. Son normas significativas que han tratado de solucionar la ambigüedad de las consecuencias económicas de este contrato a su finalización, en cuanto a la indemnización o compensación a que tiene derecho el agente, definiendo lo más claro posible entre estos dos componentes resarcitorios.

De acuerdo con el modelo de la CCI, en su artículo 21.1, regula una indemnización denominada good will, la cual se puede estipular en caso que a la terminación del contrato el agente demuestre que con su gestión ha conseguido nuevos clientes o aumentado los negocios con la clientela del empresario agenciado y que los beneficios consecuentes sean sustanciales y relacionados con la labor del agente. Esta indemnización no es acumulable con prestaciones de otra naturaleza, excepto que tengan su fuente en el incumplimiento del contrato. La indemnización por good will se basa en criterios de equidad, en consecuencia, se tiene en cuenta el grado de pérdida de ingresos económicos dejados de recibir por el agente con la terminación del contrato. Este modelo deja claro, los conceptos indemnizatorios provenientes del daño con los de la compensación, los cuales emergen de las ventajas generadas por la gestión del agente. Guarda una prudencia que creemos negativa para el Derecho mercantil internacional, pues el modelo advierte, precisamente, que los derechos del agente son regulados por normas de orden público estatal, sin embargo, el modelo se aparta de la regulación que sobre este aspecto tenemos en Colombia. 
En cuanto a la Directiva 86-653 de 1986 del Consejo de las Comunidades Europeas de la anterior Comunidad Económica Europea, es un esfuerzo coherente que obviamente se basaba en la necesidad de unificar un contrato de mucha importancia en el intercambio comercial de un mercado unificado a su vez.

En el aspecto que estamos estudiando, referente a las consecuencias dadas a la terminación del contrato, tenemos: que a la terminación del contrato el agente tendrá derecho a una indemnización, siempre y cuando: "hubiere aportado nuevos clientes al empresario o hubiere desarrollado sensiblemente las operaciones con los clientes existentes, siempre y cuando dicha actividad pueda reportar todavía ventajas sustanciales al empresario; y el pago de dicha indemnización fuere equitativo, habida cuenta de todas las circunstancias, en particular, de las comisiones que el agente comercial pierda y que resulten de las operaciones con dichos clientes." (Directiva 86-653, Art. 17.2., a). Este criterio de indemnización no fundado en criterios proteccionistas, como ocurre en Colombia, está condicionado a que la actividad del agente genere ventajas sustanciales al empresario aun después del fin del contrato. También responde a criterios de equidad, por la pérdida de clientes del agente. Entendemos que la carga de la prueba está en el agente si demanda el pago de esta indemnización.

La directiva plantea también, un límite en la cuantía de la indemnización al promedio anual de las comisiones recibidas por el agente durante los últimos cinco años. (Directiva 86-653, Art. 17. 2. b)

"Las indemnizaciones que reclame el agente según lo antes mencionado, no le menoscaban el derecho para pedir indemnización por daños, causado por el empresario." (Directiva 86-653, Art. 17. 2. c).

La regulación de la Directiva art. 17, num. 3, en aspectos consecuentes a los derechos del agente a la terminación del contrato, gravita en conceptos compensatorios, basándose en los efectos negativos que sufre el agente, relacionados directa y proporcionalmente con el beneficio sustancial del empresario que ha terminado anticipadamente e injustificadamente el contrato. Gravitando en las siguientes condiciones: 
- La privación del agente de las comisiones que hubiere recibido en condiciones normales de ejecución del contrato, correlativas a los beneficios recibidos por el empresario.

- La amortización de los gastos en que hubiere incurrido el agente para la ejecución de los negocios encargados por el empresario.

\section{El contrato de agencia ejecutado en Colombia}

Como se ha mencionado previamente, el artículo 1328 del Código de Comercio Colombiano, es una norma aunada a los artículos regulatorios del contrato de agencia, con vocación proteccionista para el agente, y son una "piedra en el zapato" para la dinámica del derecho mercantil internacional, como ya se ha afirmado. El aspecto que engendra tal protección, sin duda son los derechos a favor del agente a la terminación del contrato, que en nuestra normatividad son demasiado amplios y no distinguen entre conceptos compensatorios o indemnizatorios de proteccionistas, incluso el mismo legislador la entiende como prestación, situación que perversamente puede confundirse con nociones del derecho laboral.

Para la Corte Suprema de Justicia, es posible la renuncia por parte del agente a los derechos establecidos en el artículo 1324, pero después de la terminación del contrato (Sentencia 022, 1980). Para la Corte, las partes pueden modificar situaciones contractuales pactadas dentro del contrato después de su terminación; ahora bien, porque no pueden entonces plantearse modificaciones en otros aspectos, como es la ley aplicable. Entonces, siguiendo la posición de la Corte, las partes pueden, a la terminación del contrato, pactar una cláusula de arbitraje y de tribunal que sesionará en un país diferente al de las partes, eligiendo las disposiciones internacionales, como podrían ser las disposiciones sobre agencia de la CCI.

La vía del arbitraje puede llevar a las partes a sortear la imposición de la ley colombiana, siempre y cuando sea un contrato de agencia internacional. En consecuencia, es posible la no aplicación al artículo 1328 si se dieran las siguientes circunstancias fácticas y jurídicas: que 
el contrato tenga elementos que lo vinculen a legislaciones diferentes a la nuestra, que las partes no hayan elegido ley aplicable, que exista una estipulación de pacto arbitral y que se trate de arbitraje internacional. Quedando en manos del tribunal la definición de la ley del contrato, que no será la del foro de ninguna de las partes.

Según Aertuch (1999), "la primera consecuencia de que los árbitros no disponen de un sistema de normas de conflicto que solucione con carácter definitivo los numerosos conflictos de leyes que pueden plantearse. $\mathrm{O}$, formulado desde un punto de vista positivo, disponen de una total libertad para elegir el sistema jurídico que va a regir la cuestión controvertida, a salvo siempre la posible elección de las partes al respecto"

Otra situación que puede considerarse, es que el contrato de agencia se ejecute en Colombia y en otro país; en ese orden de ideas, según la regla de conflicto planteada por el Derecho internacional privado, habrá doble regulación. Sin embargo, si los nexos más estrechos con el contrato fueren del país extranjero, la ley aplicable no sería la local. Esta situación, aunada a la cláusula arbitral de tribunal internacional, puede generar en caso de no elección expresa de ley, que sea el tribunal el que la elija.

Dada la fuerza vinculante del artículo 1328 no sería posible que la sola nacionalidad extranjera del empresario lleve a la no aplicación de la norma, a pesar de que según la doctrina del "elemento extranjero puro" se trataría de una agencia internacional. Para poder escapar del precepto normativo, deberán estar presentes otros elementos de extranjería.

Como conclusión, las normas sobre agencia comercial deben adecuarse a modelos más congruentes con las dinámicas de la globalización de la economía y de la tendencia de mercados unificados que no muestren normas proteccionistas para el agente sino que entiendan a éstos como verdaderos empresarios con capacidad decisoria suficiente a la hora de celebrar y ejecutar el contrato, además, le otorgan resarcimiento y compensación a la finalización del mismo siempre y cuando su contribución a su contraparte lo justifique. 


\section{Del contrato de franquicia}

Se ha dicho que este contrato nace en los Estados Unidos de América (Arce, 1992), y que básicamente es una suerte de licencia o concesión mercantil (Guyenot, 1977) entre dos partes: el concedente denominado franquiciador, franquiciante o franchisor, y un concesionario o licenciatario, identificado como franquiciado, franquiciatario o franchisee.

Se trata también de un contrato atípico, sin embargo, es un negocio jurídico conocido en el sector del comercio y de él se ha disertado en la academia y en las aulas universitarias. Pero mientras no se generen normas regulatorias para este modelo de negocio, su limitante será que tiene la autonomía privada, esto es la ley, el orden público y las buenas costumbres.

Para entender lo que sucede con el contrato de franquicia dentro de la concepción de la tipicidad y atipicidad debemos decir que se trata de un contrato con ausencia de regulación legal pero con tipicidad social, pues desde hace tiempo este modelo se viene celebrando en Colombia y los empresarios lo conocen. En ese orden de ideas, la doctora María del Carmen Gete (1979, p. 21) al respecto dice: "entonces, lógicamente frente a una tipicidad que pudiera denominarse legal y que aparece en la descripción y regulación que efectúan el Código Civil y leyes especiales; cabe hablar de una tipicidad social".

Para el año 1997, el Ministerio de Justicia y del Derecho, diseñó un Plan de Armonización de Derecho Internacional Privado (PADIP) como instrumento encargado del estudio y adopción de las normas y modelos de derecho uniforme, donde se proyectó la adopción de un modelo jurídico de franquicia, desistiendo de la iniciativa de creer que no se daban las condiciones necesarias y que era mejor mantener la iniciativa de regulación e instrumentación de contrato de franquicia por las empresas internacionales y que imponer una normatividad afectaría la inversión extranjera.

Las modalidades de franquicia operan gracias a los productos o servicios ofrecidos por un empresario que los ha posicionado con éxito, y que otro empresario ve como oportunidad de negocio al favorecerse de la reputación ganada por el franquiciador. 
Se trata de un contrato sinalagmático donde el franchisor concede un producto aunado a su marca y forma de comercialización, good will etc. a la otra parte, franchisee, a cambio de un canon por el privilegio y una regalía o royalty sobre las ventas.

Señala Vítolo (1994) que "el contrato de franquicia es un convenio consensual, escrito, bilateral en el cual el otorgante ofrece individualmente a muchos tomadores, que forman un sistema de distribución o comercialización de su producción, vender o distribuir bienes y servicios en forma exclusiva y bajo el control de éste, al amparo de una marca, nombre comercial o enseña, propiedad del otorgante y de conformidad con un método, sistema o plan preestablecido por éste contra el pago de un canon y otras prestaciones adicionales"

Para el profesor Marzorati (2008), la dinámica de la franquicia se distingue de una tradicional o de producto, que consiste básicamente en la venta de sus productos a un comerciante autorizado, quien los vende a un precio más alto. La asistencia y seguimiento al franchisee no es intensa, mientras lo que el autor denomina bussines format franchising, el franchisor, no solo concede la comercialización del producto o servicio, además, confiere un método de administración y manejo de una forma de negocio, controlado y asistido de manera estricta, en la cual el franchisee es totalmente pasivo.

El Reglamento 4087 de 1988, de la Comisión de la anterior Comunidad Económica Europea, manifiesta que: "se pueden distinguir varios tipos de franquicia de acuerdo con su objeto: [1]a franquicia industrial se refiere a la fabricación de productos; la franquicia de distribución se refiere a la venta de productos; y la franquicia de servicios se refiere a la prestación de servicios."

Señala el profesor Farina (1999) que "tras la publicación de la California Investment Act, surgieron, en los Estados Unidos de América, una multitud de leyes estatales en la materia y finalmente varias normas de rango federal". Esto nos indica que a pesar de existir regulación en aquel país para este tipo de contrato, ésta es diversa, lo que de cierta manera deja abierta amplias posibilidades de interpretación y estipulación por quienes lo celebran. 
Si ponemos en contexto, en Colombia la franquicia estaría prácticamente a merced de las estipulaciones de la parte dominante de este contrato que generalmente es el franquiciante, quien llega con un formato preestablecido sobre el cual, el franquiciado, solo puede manifestar su aceptación o rechazo.

En la región suramericana, este contrato es atípico legalmente, verbigracia en Chile $^{9}$, donde tiene una suerte de regulación pero de tipo aduanera, lo cual deja su diseño como lo hemos manifestado al franquiciante; es también atípico en Perú, Ecuador y Argentina.

Ahora, es menester, siguiendo el orden lógico de este escrito, analizar cuándo el contrato de franquicia-franchising es internacional, con lo cual deberá tener entonces elementos extranjeros, sin embargo, cuando el franquiciante ofrece franquicias en otros países, sin duda ésta será internacional, desde cualquiera de los ángulos de las partes contratantes.

Si se trata de una franquicia internacional, no vemos obstáculo para que las partes elijan la ley libremente, incluso los principios UNIDROIT sobre Contratos Comerciales Internacionales, por ser un contrato comercial, lo que atañe a sus obligaciones reciprocas, son asuntos estrictamente ius privatista. Sin embargo, cualquier afectación a los consumidores, respecto de los productos, será regulado en cuanto a su protección por la Ley 1480 (2011), Estatuto del Consumidor, por ser norma de orden público, según lo previsto en el artículo 4 de la mencionada ley.

La franquicia internacional, según la manera en que se pacte la red de distribución, puede ser de dos formas, la franquicia de desarrollo y la franquicia maestra o "master franchise". En la primera, el franquiciante le otorga la exclusividad en un territorio determinado que puede ser un país o regiones de éste, para que el franquiciado, desarrolle bajo su cuenta y riesgo la apertura de establecimientos. Es decir, el franquiciado será quien despliegue el desarrollo de los establecimientos abier-

\footnotetext{
${ }^{9}$ En Chile existe una regulación de tipo de franquicia aduanera contemplada en la Ley $\mathrm{N}^{\circ} 17238$ para importación de vehículos para incapacitados. La franquicia consiste en que la persona que se acoge a ella paga sólo el $50 \%$ de los derechos de aduana entre otras prerrogativas tributarias.
} 
tos al público. La contraprestación para el franquiciante proviene de la inversión de entrada y la regalía pactada por las ventas.

En la franquicia maestra, el franquiciante le permite al franquiciado celebrar otras franquicias, a diferencia de la anterior, la responsabilidad puede difuminarse en los subfranquiciados.

Ghersi (2002) dice que ésta es la modalidad más recurrida para los casos de franquicia comercial internacional. En esta modalidad, el titular le otorga al franquiciado, el privilegio exclusivo de subfranquiciar e instalar unidades propias dentro de un determinado territorio.

La franquicia maestra, también conocida como franquicia piloto, permite que el primer franquiciado pueda obrar como franquiciante posterior, adquiriendo la obligación de transferencia del know how y acompañamiento a los nuevos franquiciados.

En el escenario que se cierne para el franquiciado, es importante que al momento de la elaboración del contrato el equilibrio contractual se mantenga, respetándose el principio de la buena fe en los negocios, propios del derecho mercantil internacional.

Es importante que en la negociación se definan de manera clara las obligaciones de las partes en el contrato de franchising, así como los elementos sensibles en la ejecución del mismo. Dado que el objeto del contrato comprende un proceso de concesión de marcas, comercialización y cesión del know how, es importante que se definan la exclusividad territorial, tanto para el franquiciante como para el franquiciado, el royalty que debe pagar el franchisee, los volúmenes mínimos de ventas que debe lograr durante ciertos periodos, la limitación y forma de transmisión de los derechos de propiedad industrial concedidos al franquiciado (franchisee) y la obligación relativa la manejo de información tipo secreto empresarial, y la manera en que el franquiciante (franchisor) va a acompañar, dirigir y asesorar los montajes de los establecimientos, mercadeo y promoción del negocio del franquiciado.

Como el contrato de franquicia implica inversiones importantes para los franquiciantes, es perfectamente lógico que se desarrollen negociaciones previas, encuadrándose una etapa precontractual, donde debe 
cumplirse como lo hemos dicho con el deber de obrar de buena fe, lo cual implica al franquiciador la obligación de ofrecer información fidedigna y real acerca de las posibilidades reales de la implementación del negocio bajo este modelo, a efecto de que el franquiciado tenga lo más claro posible sus perspectivas económicas. En ese orden de ideas, implicaría incumplimiento del franchisor si no entrega la información suficiente o ésta no está ajustada a la realidad económica. Este aspecto es regulado por la Ley Modelo sobre la Divulgación de la Información en Materia de Franquicia, elaborado por la UNIDROIT; no es claro porqué las partes no lo puedan adoptar a su contrato, si éste goza o sufre de atipicidad, es internacional, por lo cual la autonomía privada tiene mayores alcances que los contratos regulados en el derecho interno.

La ley modelo exige al franquiciante que entregue un documento de información con una propuesta de contrato con una anticipación no menor de 14 días antes de que se firme algún instrumento contractual, o que se realice algún tipo de pago por parte del franquiciado.

El artículo 6 de la Ley Modelo describe un exigente y extenso contenido de información que el franquiciante debe entregar al franquiciado, de tipo financiero, económico, jurídico, siendo poco probable que un empresario dueño de franquicias quiera dar, sin embargo, el franquiciado debe estar atento a verificar la mayor parte los aspectos que le generen riesgo por su participación en el contrato. Debe quedar claro que la ley modelo, como es la práctica de la UNIDROIT, no es un convenio ni una norma coercitiva, se trata de un compendio normativo generado para dar uniformidad al contrato de franquicia que puede ser tomado por los legisladores como punto de partida para la construcción de normas sobre franchising.

En Alemania, por ejemplo, Navas \& Mosquera (2009) referencian el fallo: Oberlandesgericht München olg München (Tribunal Superior del Territorio Judicial de München de 01.08.2002 - 8 U 5085/01, fuente: BB 2003, p. 443), en el cual se dice que "[s]i el franquiciado ha sido engañado en la etapa precontractual en torno al nivel de facturación esperado en la franquicia, el franquiciador estará obligado a indemnizar cuando las cifras pronosticadas no se encuentran justificadas en la realidad de la franquicia y estas cifras fueron decisivas para la manifestación de la voluntad del franquiciado en el contrato de franquicia." 
Según el artículo 8 de la Ley Modelo, los sistemas de remedio en caso de que el documento de información no se entregó dentro de los plazos establecidos, omitió un hecho significativo o conduce a error sobre este hecho; el franquiciado podrá mediante una comunicación escrita entregada al franquiciante con una anticipación de treinta días, dar por terminado el acuerdo de franquicia y/o solicitar la indemnización de perjuicios directamente originados por la omisión de las obligaciones de información descritas. No es posible reclamar la indemnización si el franquiciado ha accedido a la información por otros medios, o no haya sido inducido a error. El término que el franquiciado tiene para apelar a los remedios que ofrece el modelo, se deben ejercer a más tardar al año en que ocurrieron los actos o las omisiones que condujeron a la terminación del contrato de franquicia, para la indemnización de perjuicios tres años.

Ahora bien, las partes pueden pactar cláusula compromisoria para que un tribunal de arbitraje internacional dirima las controversias. En cuanto a la ley aplicable, las partes pueden elegir los principios UNIDROIT de 2004, sobre los contratos comerciales internacionales, o la ley del franquiciante parte dominante del contrato. Sin embargo, si las partes omitieran tal elección, entonces se estaría en los cauces del derecho colombiano, de acuerdo con el artículo 869 (Decreto 410, 1971), donde no existe regulación especial al respecto del franchising. El carácter internacional de la franquicia, los elementos de extranjería relevantes, la no existencia de normas explicitas de regulación, no existe razón suficiente que impida, incluso en silencio de ley aplicable, sí el pacto arbitral conlleva a un arbitraje internacional, que este elija un normatividad diferente a la colombiana, a pesar de que su ejecución se produzca en territorio colombiano.

\section{REFERENCIAS}

Aertuch, E. (1999). Derecho del Comercio Internacional. Madrid: Editorial Eurolex. 480.

Arce, J. (1992). El Contrato de Franquicia. México: Editorial Themis.

Arrubla, J. (2004). Contratos Mercantiles Tomo I. 11ª Ed. Bogotá: Editorial DIKE. 
Carrascosa, J. (2003). Configuración Básica del Contrato Internacional. Madrid: Editorial Colex.

Consejo de las Comunidades Europeas. (1986). Directiva 86-653. (Diciembre 18 de 1986. Relativa a la coordinación de los derechos de los Estados Miembros en lo referente a los agentes comerciales independientes. Recuperado de: http://civil.udg.edu/epclp/texts/es/86-653.htm

Escobar, S. (1987). Negocios Civiles y Comerciales Tomo I. Bogotá: Universidad Externado de Colombia.

Farina, J. (1999). Contratos Comerciales Modernos Tomo I. Buenos Aires: Editorial. Astrea.

Gete, M. (1979). Estructura y Función del Tipo Contractual. Barcelona: Editorial Bosch.

Ghersi, C. (2002). Contratos civiles y Comerciales, Tomo II, $5^{\circ}$ Ed. Buenos Aires: Editorial Astrea.

Guyenot, J. ¿Qué es el franchising? Concesiones comerciales. Buenos Aires: Ediciones Jurídicas Europa América.

Instituto Internacional para la Unificación del Derecho Privado. (2010). Principios Unidroit sobre los Contratos Comerciales Internacionales. Roma: Intercontinental Editora.

Londoño, M. (2005). El Contrato de Franquicia Internacional en Colombia. Foro del Jurista, (26), 137-146. Medellín: Ediciones Tinta Fresca.

Marzotati, O. (2008). Sistemas de Distribución Comercial. Buenos Aires: Editorial Astrea.

Messineo, F. (1971). Manual de derecho civil y comercial. Buenos Aires : Ediciones Jurídicas Europa-América.

Moya, J. (2003). Derecho de los Negocios Internacionales Alcances, Agencia Internacional: Armonización de los Regímenes Nacionales Como Condición Para La Competencia. Bogotá D.C.: Universidad Externado de Colombia.

Navas, M. \& Mosquera, A. (2009). El Contrato de Franquicia: Aportes y Tendencias. En: El Derecho Comparado sobre la Responsabilidad del Franquiciador. Revista Vniversitas, (119): 279-304

Organización de las Naciones Unidas. Comisión de las Naciones Unidas para el Derecho Mercantil Internacional. (1985). Ley Modelo de la CNUDMI sobre Arbitraje Comercial Internacional. Recuperado de: https://www.uncitral.org/pdf/spanish/texts/arbitration/ml-arb/07-87001_Ebook.pdf 
Organización de las Naciones Unidas. Comisión de las Naciones Unidas para el Derecho Mercantil Internacional. (1992). Convención de Viena sobre Compraventa Internacional de Mercaderías. Recuperado de: https://www. uncitral.org/pdf/spanish/texts/sales/cisg/V1057000-CISG-s.pdf

Oviedo, J. (2007). Campo de aplicación de la Convención de Naciones Unidas sobre compraventa internacional de mercaderías. Documento para la Maestría en Derecho. Bogotá: Universidad Sergio Arboleda.

Oviedo, J. (2003). Aplicaciones de los principios de UNIDROIT a los contratos comerciales internacionales. Criterio Jurídico, (3), 35-72. Bogotá: Sello Editorial Javeriana.

Parra, C. (2001). El Nuevo Derecho Internacional de los Contratos. Barcelona: Editorial Bosh.

Pérez, E. (2002). Derecho internacional privado. Vol. I. Madrid: Universidad Nacional de Educación a Distancia (UNED).

Ravassa, G. (2004). Derecho Mercantil Internacional, Principios y Normas. 2 Ed. Bogotá: Ediciones Doctrina y Ley.

República de Colombia, Congreso de la República. Ley 1480 (12 de Octubre de 2011). Por medio de la cual se expide el Estatuto del Consumidor y se dictan otras disposiciones. Diario Oficial 48.220. Bogotá, D. C.: Imprenta Nacional de Colombia.

República de Colombia, Congreso de la República. Ley 1563 (12 de Julio de 2012). Por medio de la cual se expide el Estatuto de Arbitraje Nacional e Internacional y se dictan otras disposiciones. Diario Oficial 48.4890. Bogotá, D. C.: Imprenta Nacional de Colombia.

República de Colombia. Corte Suprema de Justicia. Sala de Casación Civil. Sentencia 022. Diciembre 2 de 1980. Magistrado Ponente: Germán Giraldo Zuluaga.

República de Colombia. Corte Suprema de Justicia. Sala de Casación Civil. Expediente 4701. Octubre 31 de 1995. Magistrado Ponente: Pedro Lafont Pianetta.

República de Colombia. Presidencia de la República. Decreto 410. (Marzo 27 de 1971). Por el cual se expide el Código de Comercio. Diario Oficial 33.339. Bogotá, D. C.: Imprenta Nacional de Colombia.

Secretaría General del Consejo de las Comunidades Europeas. (1980) Convenio sobre la ley aplicable a las obligaciones contractuales. Recuperado de: http://www.secola.org/db/1_01/dir_es.pdf 
Silva, E. (2010). El Contrato de Arbitraje. Bogotá: Editorial Legis.

Vallejo, F. (1999). La Agencia Comercial según la Ley. Bogotá D.C.: Editorial Legis.

Vitolo, D. (1994). Contratos Comerciales. Buenos Aires: Editorial Ad hoc.

Zapata, A. (2010). El Régimen Jurídico de los Contratos Internacionales en Colombia. Derecho Internacional de los Negocios. Bogotá: Universidad Externado de Colombia. 